\title{
Model Approach for Formation Synergy Effects in Automotive Industry with Support of Big Data Solutions
}

\author{
Martin Holubčík*, Gabriel Koman, Michal Varmus, and Milan Kubina \\ Department of management theories, Faculty of management science and informatics, \\ University of Žilina, Univerzitná 8215/1, 01026 Žilina, Slovak Republic \\ \{martin.holubcik, gabriel.koman, michal.varmus, \\ milan.kubina\}efri.uniza.sk
}

\begin{abstract}
The automotive industry within Slovak republic is currently leader of industry sector. Innovative solutions and sustainability play a key role in continuous progress of companies. Big Data solutions have currently growing and significantly impact. This article appeals for use of Big Data solutions in automotive industry and their connection to synergy effects in strategic management of automotive industry. Through these new approaches: Big Data solutions and emerging synergy effects is necessary to propose recommendation in order to successful collaborative solutions.
\end{abstract}

Keywords: Automotive industry, strategy, management, collaborative solutions, Big Data solutions, synergy, synergy effects.

\section{Introduction}

This instruction file for Word users (there is a separate instruction file for LaTeX users) may be used as a template. Kindly send the final and checked Word and PDF files of your paper to the Contact Volume Editor. This is usually one of the organizers of the conference. You should make sure that the Word and the PDF files are identical and correct and that only one version of your paper is sent. It is not possible to update files at a later stage. Please note that we do not need the printed paper.

The current business environment in all industry sectors, especially in automotive sector create new situation on market that companies are trying to solve. Growing number of companies are standing against low-cost and targeted competition, cooperation risk, customer requirements, development in new technology, progress in science and research and others determinants create new conditions for business not only at domestic market but increasingly predominant global market.

For management in these days is necessary to draw attention to the need for innovation of managerial thinking. The shift in managerial thinking is essential for proper understanding and management settings of cooperative organizational forms or others forms of cooperation. Managers need information (data) to be able have a clear

*martin.holubcik@fri.uniza.sk 
picture about market and its actors. This reflects a causal relationship in front of we need quality information. Dynamic and chaos of processes of internal and external environment of companies in which grow not only interaction but also unstructured data create one of the basic condition for forming synergy effects (evolution).

First, the starting points of synergy can be observed in many research areas, if not in all. Synergy is a core discipline of changing perception of added value generated by numbers of objects (individuals, companies, clusters, organizations, etc.). It helps to analyse and examine various of synergetic phenomena, examine conditions of potential impacts and resulting values. Here we come to a new approach of synergy as a link, connection, engagement in cooperation within a specific environment, while this environment is changing, developing and reacting. Synergy effect is based on synergy in particular environment, it create value, expected - unexpected result and state.

Second, Big data solution present processing of large amounts of heterogeneous data, and these can be the bearer of critical information value. There are mainly unstructured and semi-structured data that are generating by man, machine and their combination. This phenomenon observed in recent years, a great potential, mainly due to the rapid development in information and communication technologies. People and machines currently generate large volumes of disparate data that can be potentially carries significant information value for company, in case that company can capture and process. Timely, relevant and reliable information are mining from available data - it becoming an inherent input, background, component in decision-making of company. It is possible to consider about using Big Data solutions in almost every area of business process. The emergence of a uniform integrated data base in company, when are diverse data from across company and its environment available for the needs of strategy management. Through these new approaches: Big Data solutions and emerging synergy effects is necessary to propose recommendation in order to successful collaborative solutions.

The strategic management of companies within identified starting points provide a basis for modelling and validation of these results in practise and their further investigation. It represents a potential way (strategy management) and place (cooperative organizational forms), which is able to create synergy effects. Where Big Data solutions represent a source of values (data base), that can provide relevant and valuable information obtained by analysing various emergence of synergy phenomena and ta. Detecting pattern and key factors affect resulting potential value and impact of opportunities.

For theory and practice is create significantly new methodological approach as way how can be appropriate manage cooperative organizational forms (group of cooperative enterprises) as way to formation synergy effects and use Big Data technology.

The purpose of this article is to use this new approach in automotive industry, which is currently one of the leading industry on Slovak market.

According to Statistical Office of Slovak Republic it was at 1.1.2016 registered in Slovakia 665 big companies (over 250 employees), with 279 business covered in industrial production, it including also automotive industry (type of economic activity $\mathrm{CL}$ - manufacture of transport equipment and $\mathrm{CK}$ - machinery and equipment etc.), which representing approximately $41.2 \%$ of companies. 
The problem is continually expanding amounts of diverse data that have potentially important information value.

The objective: Based on theoretical knowledge of the issue to identify the potential of Big Data solution for purposes of synergy effects in strategic management of collaborative relations in automotive industry. These findings present case study of the resulting in theoretical and practical comprehensive research which has been processed in following text. The value of these information is enrichment of knowledge in automotive industry and potential application in industry. Methods that are used in this article are: content analysis, induction and deduction of information, logical reasoning and qualitative approach in information processing.

The research intention of this article is to introduce and demonstrate the potential of Big Data technology and their solutions in automotive industry through use synergy as approach in strategy and cooperation management.

The article following our previous publication: Cooperation as base for synergy [18]; Application of Big Data Technology in Knowledge Transfer Process between Business and Academia [22]; Evaluation of the innovative business performance [61]; Possibility of improving efficiency within business intelligence systems in companies [24].

\section{Identification of the Main Theoretical Approaches}

The synergy is one of the processes in the cooperative environment in which is increasing number of interactions and the importance of individual links between them. If a group of companies want to achieve a synergistic effect it is necessary, that the group is properly managed and that management is based on data.

The elements of cooperation in the interactive relationship between (setting goals, establishing a cooperative equilibrium, consolidate mutual trust, filtering members' cooperation, rules and standards of cooperation, maintaining mutual information and communications environment, complying with reciprocity, creating a positive experience, the combination of resources, setting of the control mechanism) are incomplete a set of recommendations for management members in cooperation. At present, is progress and development of cooperative management that addresses application management in cooperation. In a global environment where is growing diversity of members, interactions, and distances is necessary to applied cooperative management. Soviar [53] disclose cooperative management as efficient and effective relationship management in the sense of cooperation between independent from each other relatively independent organizations or individuals in order to increase their competitiveness.

Linking cooperation and synergies need to be supported with the following baseline factors:

- Cooperation in the context of evolution: According to Nowak [35], is one of the approaches of evolution just cooperation and its different forms, while adding: cooperation is necessary for the evolution to building new levels of organizations. 
- The diversity of the members of cooperation: The global environment makes the diversity of members, as stated by Axelrod [4], co-operation is common among members of the same species and also between the members of different species, it is the central idea of reciprocity.

- Interactions within cooperation: Fehr and Schmidt [16] point to determine in which one member affects the whole group cooperating with the changes in her behaviour beneficial or prejudicial within the group.

To better understand the issue of synergies and synergies is within the carried out survey comprehensive analysis on real cases (secondary data). The findings represent the following status synergies within the business environment.

Cases of cooperation are stronger than ever, not only in the past but mainly towards the future. Strategic alliances setting an example of such cooperation - an example of synergy in management (Control example of cooperation in management, organizational forms of cooperation). In 2003, the Austrian Institute "Hernstein International Management Institute", made study of 450 central European businesses, which has resulted in a high proportion (51-67\%) of the companies that used cooperative management style. However, individual interviews with managers showed that they used mostly consensual, or patriarchal and authoritarian methods of management. [52] Currently, management style resulting in increased operational capacity and aggressiveness to strengthen the company's competitiveness by creating alliances and networks. However, it depends on environmental conditions and companies situated there. According different conditions should be used different management styles.

Authors Ireland, Hitt and Vaidyanath [21] stated that most alliances end in failure, but highlighted the importance of alliances attributes. Mainly that they are source of competitive advantage and create bigger value on the market. Businesses usually seek access to relevant sources through the alliances. Management efficiency of alliances should be based on the benefits of its implementation. The whole process starts with choosing the right partner, followed by the building of social capital, knowledge and maximizing cooperation on the basis of confidence-building.

Authors Hamel, Doz and Prahalan [17] during their five years content analysis of fifteen strategic alliances focused on how companies use competitive cooperation to increase (increase, improve) their internal skills and technologies, while preventing the transfer of competitive advantages to ambitious partner. Where high investments are needed to develop and promote products to new markets where only a few companies can go separately in every situation. Cooperation is competition in a different form. Occasional conflicts are evidence of the mutual beneficial cooperation in which only a few cooperation can maintain a constant win-win strategy. The authors also argue that cooperation has its limits, and the company must defend against competitive compromise. For example, strategic alliances include constantly evolving negotiations which go beyond the realistic conditions of agreements or goals of top management. Learning from partners is paramount, but each alliance is actually a window to the wide partnership skills, build new knowledge through cooperation organizations.

Kang and Sakai [65] for the study of international strategic alliances identified providing synergistic effect. These strategic alliances, mergers and acquisitions 
expected to provide a synergistic effect in the long term by reducing the overlap between trading partners and reduce costs (critical level for the market, adding new lines of business, providing financial support for ailing businesses). Output (product) for alliances latecomer, up to several years, and their range is limited (it is characterized by a one-time collaboration in development activities). Strategic alliances prefer small companies with unique technological advantages to cooperate with larger companies with financial resources that enable them to increase core (core, unique and their own skills and knowledge of business) competencies while maintaining their independence. Initial, transaction costs are input by acquisitions and mergers are much higher than for strategic alliances.

\subsection{The Big Data Technology}

Manager's decision-making currently depend on timely, available and relevant information with context of problem solving.

The continuous development of ICT gives rise to new systems and platforms that generated in each second amount of information that can be potentially carries important information. Mentioned generated data is typically stored in different database structures. Currently the most comprehensive database structure is represent by data warehouse.

The ICT provides tools through managers obtain information what they need and use them in decision-making process. This ensures effectively decision through innovative solutions and tools, which can meet needs of managers in dealing with specific situations, i.e.: office automation, etc. [2] In current situation, business generate large volume of data. Manual and mechanical systems for converting this data into information cannot handle this large amounts, depending on time, costs and complexity of process.

From this reason the transformation of data into information is nowadays provide with complex information and communication technology in terms of information systems with distribution of information to specific needs (manager implementing decision). [3,60,26,59]

The impact of ICT on decision making of managers is crucial in terms of global exposure of company, especially for needs [2]: defining number of variants for global markets and internet; reduce uncertainty; saving time and finances; fast communication with various consultant, work teams or experts, who appear in decision-making process.

Based on these findings, it is possible assumed that information and communication technologies emerge in whole decision-making process as a supporting tool.

Information and communication technology and specific information systems allow manager to handle amount of data and transform them into relevant information through specific tools and techniques, i.e.: provide information support in different phases of decision-making process. The influence of informatization of whole society $[1,36]$, it can be assumed that trend of using information and communication technology in decision-making processes of managers will be constantly deepened 
and specified according to current needs and requirements, i.e.: need for processing unstructured data to obtain important information.

The amount of data is growing,. But business this data through traditional systems cannot store, process and use. This phenomenon is mainly due to different structure data, i.e.: unstructured and semi-structured data that processing is challenging [6]. Large volumes of unstructured data have different characteristic than data generated in business while data warehousing and data management tools can not efficiently process and analyse these amounts in terms of reasonable time and cost perspective [15] - through this reason was established Big Data technology.

The meaning of large amounts of data was recorded in seventies, when scientists from Barkeley have identified that to 1999 should be generated over 1.5 trillion information. The very basis for definition of large data (Big Data) was introduced in 2001 by Doug Laney, who called constantly-increasing amount of data by "3V", i.e.: volume, variety and velocity. The problem of large amounts of data was first mentioned in 1997, when NASA scientists have tagged problem with visualization since graphic data reached such volume that the data file could not be placed in main memory or on hard drive of computer [5,31].

Large data represent defined term that describes a large number of complex data sets, and describes advanced technologies to collect and store data [54]. It is possible to talk about large amount of data in three basic senses. Firstly data has large volume for process them in reasonably short time; second is unstructured data or those information which we need in real time.

The Big Data term refers to large amount of information coming from different sources such as transaction records, boot files, social media, sensors, web application, etc. Big Data is not only a large amount of data, but are also extremely diverse data types distributed at different speeds and frequencies (Stanimirovič and Miškovic). For Big Data we consider amount of data that we have difficulty to processing conventional, commercially available means [57]. The Big Data is next generation of data warehousing and business analysis that are ready to provide highest support for need to save costs and increase business efficiency [33].

The Big Data is data that require an excessive amount of time and space for storage, transmission, processing and use of available resources [64]. The emergence of new technologies in the field of Big Data was supported by the assumption that the amount of data generated is increasing at a rate that is at odds with the speed of development of current technologies for the processing of the data, i.e., current technology cannot save to memory generated by the amount of data. Precisely for this reason arose technology for the processing of data, MapReduce and Hadoop open platform from Google and Yahoo. The above data without having to store them in the process technologies allow arranged rows, as is the case with conventional database tables, this means that the technology can work with data without the need for a single hierarchy or homogeneity. Law firms, which have a lot of data generated in the context of the Internet, have an interest in analysing these data from different, in particular economic reasons. Therefore, these businesses are creating an initiative for the creation of new trends in the processing of the quantity of diverse data. All generated data contain some information value, which can bring different benefits to the enterprise. [27] 
The Foundation of architecture Big Data analysis tools, infrastructure and applications for the purposes of the implementation of the various operations over the available data. The current database systems are not sufficient in terms of performance and infrastructure for the processing of large volumes of disparate data. To resolve this issue, have been created by new technologies in the context of Big Data infrastructure, which include [29]: Hadoop; NoSQL; MPP (Massively Parallel Processing).

Hadoop represents a tool aimed at storing, processing and analyzing large amounts of structured and unstructured data, i.e. can work with diverse data types. Technology, analysis tools, software solutions etc. It is possible in the architecture of the Big Data expand or integrate according to the requirements of the enterprise. An example of that integration is the integration architecture Big Data with Business Intelligence.

The principle of work with the data in the context of Big Data is consistent with the principle of traditional Business Intelligence, which also applies in the case of architecture. The essential difference, however, is the type of data processed. In the framework of the enlarged Hadoob architecture (Figure 1), it is evident that the architecture of the Big Data may contain a layer of data warehouse that stores structured data in multidimensional databases for the purposes of business generated in the advanced analysis. Beyond the data warehouse and Business Intelligence layer works, or analytical tools and principles of BI, which handle structured data. Thus, Big Data technology represents a certain connecting cell among analytical tools for processing various data and at the same time the system of Business Intelligence tools. Among the key layers that are especially those that work over a lot of architecture of unstructured data that are generated in the vicinity of the enterprise, or in the real world. Include here the following layers: layer for data warehouse, data processing, layer for layer, a layer of data management and data access layer data connection. [46]

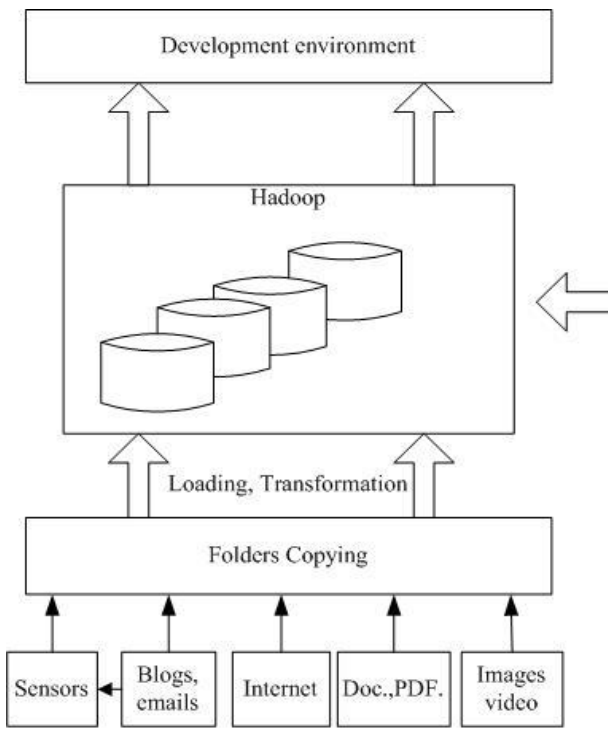

Unprocessed data flow

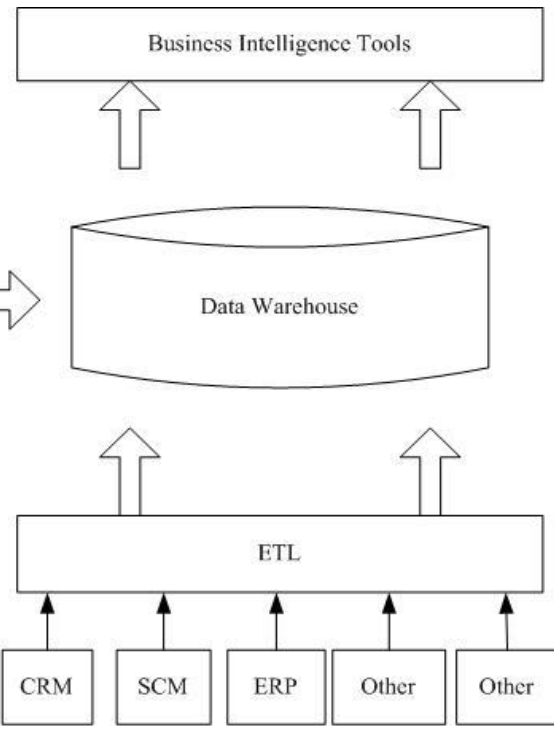

Operating system 
Similarly, in the context of Big Data system architecture integrates Business Intelligence platform, IBM'S Big Data (Fig. 1), where they are structured and unstructured data merging into a single database structure, or into a single architecture. [51]

From the above it is clear that the providers of technology integration in Big Data trying to integrate not only the analytical tools of Business Intelligence, but to link the entire infrastructure of the enterprise into a single whole with the architecture of the Big Data.

Integration of Big Data solution within company with possibility to process structured data in combination with other disparate data, that are generated in company and its external environment can provide significant information value in terms of gaining competitive advantages, increase profit or other various business areas for example $[7,8,9,13,25,39,41,44,45,49]$ :

- Effective work and evaluation of data through modern technologies and advanced analytical tools.

- Increase efficiency of marketing activities.

- Reduce the risk of loss by prediction of consumer purchasing behavior.

- Influence and shape consumers purchasing behavior on the basis of available information obtained data gained from social networks, etc.

- Adapting products according to needs and requirements of customers (i.e.: through data from the self-service cashier, camera records in store, etc.).

- The targeting of marketing campaigns (offer specific products and services to a particular customer).

- More effective workflows and processes (i.e.: in call center through the analysis of voice calls).

- Improving and extending service (eg. In the health sector by evaluating variety patient data that is generated for example by Smart and fitness equipment)

- The customer identification, prediction and detection of cheat.

- The support of logistics processes in terms of reducing product delivery, saving the shipping cost and other through the analysis of thousands delivery variants in real time.

- Optimization for supply and use of energy

- The possibility to transfer management on a data-driven organization

Obviously, Big Data solution can be used in almost any area of business. It is all about data, i.e.: Big Data solution deployment is conditional on a number of generated and used various data. Data is carriers of information value. The advanced technology and analytical tools of different platforms of Big Data solutions offer for companies the opportunity to evaluate a variety data and mine valuable information for strategy management of company. In the process of strategic management of company are used information from across whole company and also external environment. Data generated form the lowest level of management to top levels and other data sources, which information value allows the company to inspect and plan its position and future activity with regard to continually changing and turbulent market environment. In this sense, it is also possible to consider about detection of factors, in-depth analysis of available data, which gives rise to synergies and subsequently synergy 
effects. The capturing and evaluating of these phenomena enable for companies to uncover additional value or risk factors that may occur in implementation of decisionmaking on a strategic level and their impact on the lower levels of company management, processes, people and overall position on the market, i.e.: detection of synergies in the process of strategic management provide companies opportunity to harness them or prepare for possible negative impacts from implementing decision.

The most frequently is possible to observe deployment of Big Data solutions in sectors of product sales (wholesale), logistics centres (warehouse management, orders and deliveries), production (managing production program), health service (patients' health monitoring), sport (prediction matches, planning teams, investment, etc.) and so on. With powerful analytical tools is this solution deploy to support decision making in more and more areas of the business. Big Data find significant applying also in the area of automotive industry.

\section{Case Study - Solution for Automotive Industry}

The purpose of deployment of Big Data solutions in automotive industry is particularly stimulated by fast digitalizing of whole society and difficulty for collecting and processing the amount of available data. The consequence of this phenomenon is gradual or resolute transition traditional industries (as well as online) to digitalize with support of implementation processes through internet and cloudbased solutions $[14,50]$.

On basis of this solution it is expected in future decision-making in automotive industry using data and information from five dimensions [50]:

\section{- Electronics \\ - Autonomy \\ - Linking \\ - Mobile services \\ - Information}

The Big Data solution are currently used in almost every aspect of the automotive industry, such as safety, design and so on. This intervention has an impact on total production in sector and also on specific products (cars) especially in areas $[11,12,19,20,23,28,32,34,42-45,47-48,50,56,62-63]$ :

- The design, which is assessed on basis of available collected and processed data throughout life cycle of vehicles, i.e. analysis of data in real time with deployment of vehicles can identify opportunities to improve safety, aerodynamics, placing a product on market, etc.

- The acquisition, optimization of Supply chain management for improving efficiency of process by analysing amount of data from different supplier.

- The production. Through the Big Data solutions and advanced analytics is possible predict state of production line or product quality. The results of simulation can subsequently be detecting narrow spot in production process and 
improve production planning, repairing, human capital and entire production process.

- The marketing and development of products based on customer feedback and in time marketing campaigns (knowledge of customers and their needs).

- The finance under obtaining relevant information from customer behaviour is base for better understanding and developing effective funding programs across all market segments. There is a presumption on that is possible to identify opportunities for new sources of revenue for company.

- The performance in terms of gathering, analysing and evaluating information systems of vehicle and its surroundings in real-time for purposes of identifying characteristics of future generations of vehicles.

- The services and technical support will have available information about current status of vehicle. This make possible to predict and identify potential failure or dangerous situations and create action and solutions for their elimination.

- The aftermarket services based on information and knowledge of drivers combined with unstructured data needs for development of partnerships.

These examples of deployment and use Big Data solutions are just some of the number of possibilities usage in automotive industry. The digitalization of automotive industry and processing amount of diverse data is base for effectively management and planning of all processes in automotive industry. This is confirmed by investition of General Motors into human potential with number of 10,000 employees, with a focus on information technology [44,45]. It is expected that by 2020 will be $90 \%$ of cars connected to the network in terms of M2M (machine-to-machine) communication, which represent generation and sharing of large amounts of diverse data available in entire automotive industry [38].

\section{Conclusion}

The statements have been prepared and formulated not only from analysis of available information consisting in this article, but also knowledge and experience of authors.

Based on above findings it is necessary to formulate in context of forming synergy effects with supporting of Big Data solutions in automotive industry define following statements:

1.The specific solutions in the form of informational systems is necessary for obtain necessary and relevant information, which are now a vital input for decision-making at strategy management level.

2. The development and use of Big Data solutions in automotive industry represent important meaning in terms of generated disparate data that may contain potentially important information value.

3. The Big Data solution can be used in almost every field of automotive industry at strategic management by needs to streamline entire industry. 
4. The space for use of Big Data solutions is create by the existence of everexpanding disparate data. Since information obtained in these solutions may significantly affect forming synergy effects in strategy management of these processes.

5. The decision making in strategy management is influenced by uncovering synergy effects created with intensive relation on data and information.

On base of the previous facts it is need to select the following elements for the formation of proposals and applying the synergy approach Big Data solutions use in the automotive industry:

- Cooperative management style. The current capacity for action and aggression environment for strengthening the competitiveness is manifested by creating mutually beneficial interactions (such as alliances, networks, etc.).

- The environment of companies must be prepared to adapt to the use of new approaches and ways of working with data - through them the whole environment changes, develops and responds.

- The value of company, group of companies is now considered in the context of access to resources and the benefits it can provide and create. These data represent a new source of the current companies' environment, the utilization rate and proportionally increasing importance to the competitiveness of companies.

- Identifying partners for cooperation is dependent on data.

- Mutually beneficial cooperation makes goals to which it creates a win-win strategies.

- Cooperation is a window to a broad range of skills and the development of new knowledge.

Through these changes increases the intensity level of synergy in the cooperative environment and thus the occurrence of synergistic effects increases. Strategy (policy) of the company the current authors categorized into different types, which discussed in detail.

The potential of processing amount of disparate data and obtaining information lead to an improvement in many ways (driving performance of cars, avoidance of accident, increase customer satisfaction, etc.). It can ultimately cause a synergy effect to level of strategy management in production to efficiency automotive industry.

One of these strategies is just cooperation, cooperation with automotive companies in a certain area within defined conditions and competitive fight. The product of such interactions can also be synergy.

If the cooperation is necessary for the creation of synergies, then through the strategic management of cooperative organizational forms can be obtained synergistic effect in the automotive company environment. This effect is a new critical factor of success of the present, more and more, globalized environment.

The digitalization of automotive industry and processing amount of diverse data is base for effectively management and planning of all processes in automotive industry. With powerful analytical tools is this solution deploy to support decision making in more and more areas of the business. Big Data find significant applying in the area of automotive industry. 
We put higher importance to focus on new successful collaborative solutions. This case of application suggested statements of using Big Data solutions in automotive industry to create synergy effect based on cooperative environment is starting point to realize deeper research in the previous context in certain automotive area.

Acknowledgements. This work was supported by the Slovak Republic scientific grants VEGA 1/0617/16; VEGA 1/0621/14 and APVV-15-0511.

\section{References}

1. Best practice guideline: Big Data, http://datascienceassn.org/sites/default/files/Big\%20Data\%20Best\%20Practice\%20Guideli ne.pdf

2. ICTs for decision making problems and prospects, http://www.gu.edu.pk/New/GUJR/PDF/Dec-2009/5\%20Qammar\%20Afaq\%20Paper $\% 201 . p d f$

3. ALDEA, C.C., Popescu, AD., Draghici, A., Draghici, G.: ICT Tools Functionalities Analysis for the Decision Making Process of Their Implementation in Virtual Engineering Teams. Procedia technology 5, pp. 649--658 (2012)

4. Axelrod, R., Hamilton, W.D. The evolution of cooperation. Science 211, pp. 1390-1396 (1981)

5. The Impact of Information Technology in Facilitating Communication and Collaboration in Libyan Public Sector Organisations, http://itc.scix. net/data/works/att/w78-2009-1-61.pdf

6. BUDAY, T. (2011) Unconventional sources of data for conventional BI systems (in Slovak), http://beta.itnews.sk/temy/5-2011/2011-05-12/139761-nekonvencne-zdroje-datpre-konvencne-systemy-bi

7. How UPS Uses Big Data With Every Delivery, http://businessintelligence.com/big-datacase-studies/ups-uses-big-data-every-delivery/

8. Macy's Gets A Leg Up On Competition With Business Intelligence, http://businessintelligence.com/big-data-case-studies/macys-gets-leg-competition-businessintelligence/

9. Tesco's Legendary Big Data Benefits, http://businessintelligence.com/big-data-casestudies/tescos-legendary-big-data-benefits/

10. ČERNÝ, M. Eight technology trends that transform libraries in the information society (in: Czech). ITlib 2, 30--36 (2013)

11. Big Data in the Automotive Industry, http://www.csc.com/auto/insights/103241big data in the automotive industry

12. Connected Car Fleet Management with Big Data Analytics, https://www.datameer.com/company/datameer-blog/connected-car-big-data-automotiveindustry-future/

13. Big Data in big companies, International institute for analytics, http://www.sas.com/resources/asset/Big-Data-in-Big-Companies.pdf

14. Big data and analytics in the automotive industry, https://www2.deloitte.com/us/en/pages/manufacturing/articles/big-data-and-analytics-inthe-automotive-industry.html

15. Big Data. New ways of processing and analyzing large volumes of data, https://www.systemonline.cz/clanky/big-data.htm 
16. Fehr, E., Schmidt, K.M.: A theory of fairness, competition, and cooperation. Harvard College and the Massachusetts Institute of Technology. The Quarterly Journal of Economics 114, pp. 817--868 (1999)

17. HAMEL, G., Doz, Y., Prahalad, C.K.: Collaborate with your competitors - and win. Harward business review (1989)

18. Holubčík, M.: Cooperation as base for synergy. eXclusive e-Journal. Issn: 1339-4509 (2015)

19. Fast-track automotive innovation, https://www.hpe.com/h20195/v2/GetPDF.aspx/4AA65167ENW.pdf

20. Digital disruption and the future of the automotive industry, https://www935.ibm.com/services/multimedia/IBMCAI-Digital-disruption-in-automotive.pdf

21. Ireland, R.D., Hitt, M.A., Vaidyanath, D.: Alliance Management as a Source of Competitive Advantage. Journal of Management 28, pp. 413--446 (2002)

22. Koman, G., Kundrikova, J.: Application of Big Data Technology in Knowledge Transfer Process between Business and Academia. Procedia Economics and Finance 39, pp. 605-$611(2016)$

23. Global Automotive Executive Survey 2016, https:/home.kpmg.com/xx/en/home/insights/2015/12/kpmg-global-automotive-executivesurvey-2016.html

24. Kubina, M., Varmus, M., Kubinova, I.: Possibility of improving efficiency within business intelligence systems in companies. Procedia - Economics and finance 26, pp. 300--305 (2015)

25. 7 Reasons Why Big Data easier for enterprises to life, http://www.zive.sk/clanok/66175/7dovodov-preco-big-data-ulahcia-firmam-zivot

26. Marielle, D.H., Sol, G.H. The Impact of Information and Communication Technology on Interorganizational Coordination: Guidelines from Theory. Informing Science - Special Series on Information Exchange in Electronic Markets 4, 129--138 (2001)

27. Mayer-Schonberg, V., Cukier, K.: Big data: a revolution that will transform how we live, work, and think. John Murray Publishers (2013)

28. Car data: paving the way to value-creating mobility. Perspectives on a new automotive business model, https://www.mckinsey.de/files/mckinsey car data march 2016.pdf

29. MCNULTY, E. (2014) Understand Big Data: Infrastructure, http://dataconomy.com/2014/06/understanding-big-data-infrastructure/

30. Understand Big Data: The Ecosystem, http://dataconomy.com/2014/06/understanding-bigdata-ecosystem/

31. What Is 'Big Data,' Anyway?, http://www.strategy-business.com/blog/What-Is-Big-DataAnyway?gko $=28596$

32. The Automotive Industry as a Digital Business, http://www.ntti3.com/blog/the-automotiveindustry-as-a-digital-business/

33. Minelli, M., Chambers, M., Dhiraj, A.: Big Data, big analytics. Emerging Business Intelligence and analytic trends for Today's businesses (2013)

34. Nedelcu, B.: About Big Data and its Challenges and Benefits in Manaufacturing. Database Systems Journal 4, pp. 10--19 (2013)

35. Nowak, M. A.: Five rules for the evolution of cooperation. Science 8, pp. 1560--1563 (2006)

36. Ogbomo, O.M., Ogbomo, F.E. Importance of Information and Communication Technologies (ICTs) in Making a Healthy Information Society: A Case Study of Ethiope East Local Government Area of Delta State, Nigeria. Library Philosophy and Practice, Issn: 1522-0222 (2008)

37. Model of handling Big Data and knowledge management in automotive industry, https://ideas.repec.org/h/tkp/mklp16/731-740.html 
38. Connectivity in the Automotive Sector,

http://www.pinsentmasons.com/en/media/publications/connectivity-in-the-automotivesector/

39. Big Data Case Study: Tesco, http://www.speakersconnect.com/robert-plant-big-data-casestudy-tesco/

40. How To Build A Secure Connected Car, http://www.forbes.com/sites/ibm/2014/11/10/howto-build-a-secure-connected-car/\#56891 ee44e40

41. 12 Big Data Definitions: What's Yours?, http://www.forbes.com/sites/gilpress/2014/09/03/12-big-data-definitions-whatsyours/\#41a8246e21a9

42. RampelliI, S. Vadlamani, S.K., Nukala, S.P.K.: Big Data and Data Analytics: An Action Platform for the Science of Prediction. Journal of Engineering Research and Applications 4, pp. 24--27 (2014)

43. Big Data Is Driving Your Car, https://www.linkedin.com/pulse/iot-big-data-preventativepredictions-matthew-reaney?trk $=\mathrm{mp}$-reader-card

44. Walmart Makes Big Data Part of Its DNA, https://datafloq.com/read/walmart-making-bigdata-part-dna/509

45. Self-driving Cars Will Create 2 Petabytes Of Data, What Are The Big Data Opportunities For The Car Industry?(, https://datafloq.com/read/self-driving-cars-create-2-petabytes-dataannually/172

46. Big data is Scaling BI and Analytics, http://www.informationmanagement.com/issues/21 5/big-data-is-scaling-bi-and-analytics-10021093-1.html

47. How is Big Data impacting sales in the automotive industry?, http://docplayer.net/10728874-Big-data-how-is-it-impacting-sales-in-the-automotiveindustry.html

48. The Connected Vehicle: Big Data, Big Opportunities, http://www.sas.com/content/dam/SAS/en us/doc/whitepaper1/connected-vehicle107832.pdf

49. "Big" with a company that won the big data (in: Slovak), http://businessworld.cz/analyzy/big-firmy-to-s-big-daty-vyhraly-11472

50. The Automotive Industry's Big Data Callenge (Part 2), https://corporateinnovation.co/2016/02/11/the-automotive-industrys-big-data-challenge-part-2/

51. Big Data: From great expectations to practical use (in Slovak), https://www.systemonline.cz/business-intelligence/big-data-od-velkych-ocekavani-kpraktickemu-vyuziti.htm

52. Souček, Z.: The company of the $21^{\text {st }}$ century. (in Slovak), Professional Publishing, Praha. ISB 80-86419-88-6. (2005)

53. Soviar, J., Lendel, V., Kocifaj, M., Čavošová, E.: Cooperation Management (in Slovak), EDIS, Žilina (2013)

54. Hu, W., Kaabouch, N.: Big Data Management, Technologies, and Applications. In: Information Science Reference, pp. 222--269 (2014)

55. Statistical Office of the Slovak Republic. Businesses: by legal forms of economic activities (NACE Rev. 2) the size and number of employees, https://slovak.statistics.sk

56. Stricker, K., Wegener, R., Anding, M.: Big Data revolutioniert die Automobilindustrie. Bain \& Company (2014)

57. Synek, T.: How to cut IT costs by using big data technologies. (in Slovak) INFOWARE 10, pp. 23--24 (2014)

58. The Automotive Industry's Big Data Callenge (Part 1), https://corporateinnovation.co/2016/01/25/the-automotive-industrys-big-data-challenge-part-1/

59. ERICSSON. Unhabitat for a better urban future. The role of ICT in the new urban agenda (2014) 
60. Ujunju, O.M., Wanyembi, G., Wabwoba, F. Evaluating the Role of Information and Communication Technology (ICT) Support towards Process of Management in Institutions of Higher Learning. International Journal of Advanced Computer Science and Applications. 3, pp. 55--58 (2012)

61. Varmus, M., Lendel, V.: Evaluation of the innovative business performance. Procedia social and behavioural science. 129 , pp. 504--511 (2014)

62. Three Ways Big Data Is Helping To Build Better Cars, http://www.forbes.com/sites/ibm/2014/12/18/3-ways-big-data-is-helping-to-build-bettercars/\#ae4cc4826e30

63. Wyman, O.: Implementing Big Data is the hardest part, http://www.oliverwyman.de/insights/publications/2015/jul/implementing-big-data-is-thehardest-part.html\#.WHyD91PhCM8

64. Yildirim, A., Özdoğan, C., Watson, D.: Parallel Data Reduction Techniques for Big Datasets. Big Data Management, Technologies, and Applications. In Information Science Reference, 72-93 (2014)

65. Kang, NH., Sakai, K.: International Strategic Alliances. OECD Science, technology and Industry, Issn: 1815-1965 (2000) 